\title{
Effect of Tai Chi exercise for hypertension: a meta-analysis of randomized controlled trials
}

\author{
Yeting Zhang ${ }^{1}$, Yan Fu ${ }^{2}$,a , Bin Zhu', Chuikun $\mathrm{Li}^{1}$ and Xueling $\mathrm{Lin}^{3}$ \\ ${ }^{1}$ Institute of Physical Education, Chengdu University, Chengdu, China \\ ${ }^{2}$ Institute of Physical Education, Southwest University for Nationalities, Chengdu, China \\ ${ }^{3}$ Institute of Physical Education, Yangtze University, Jingzhou, China
}

\begin{abstract}
Objectives: We designed this study to evaluate the effect of Tai Chi exercise for hypertension patients. Methods: RCTs designed to evaluate the effect of Tai Chi exercise for hypertension patients were searched from Science Direct, EBSCO, Pub Med, CNKI and Wanfang databases. Results: The meta-analysis found that (ATC) the SBP (WMD $=13.19$ $\mathrm{mmHg}$; 95\%CI: 11.52 to $14.87 ; \mathrm{P}<0.0001)$ and $\mathrm{DBP}(\mathrm{WMD}=8.92 \mathrm{mmHg}$; $95 \% \mathrm{CI}$ : 7.94 to $9.90 ; \mathrm{P}<0.0001)$ can be significantly reduced after Tai Chi exercise compared to before Tai Chi exercise (BTC). ATC significantly improved the content of $\mathrm{NO}$ (WMD $=-7.98 \mathrm{mmol} / \mathrm{L} ; 95 \% \mathrm{CI}$ : -10.63 to $-5.33 ; \mathrm{P}<0.0001)$, and decreased the content of TG $(\mathrm{WMD}=0.22 \mathrm{mmol} / \mathrm{ml} ; 95 \% \mathrm{CI}$ : 0.06 to $0.38 ; \mathrm{P}=0.006)$ and $\mathrm{LDL}-\mathrm{C}(\mathrm{WMD}=0.20 \mathrm{mmol} / \mathrm{ml} ; 95 \% \mathrm{CI}: 0.13$ to $0.26 ; \mathrm{P}<0.0001)$. There was no obvious difference between ATC and BTC on HR (WMD $=1.64 ; 95 \% \mathrm{CI}:-0.51$ to $3.97 ; \mathrm{P}=0.14)$, TC $(\mathrm{WMD}=-0.03 \mathrm{mmol} / \mathrm{ml} ; 95 \% \mathrm{CI}:-0.22$ to $0.17 ; \mathrm{P}=0.80)$ and HDL-C $(\mathrm{WMD}=-0.04 \mathrm{mmol} / \mathrm{ml} ; 95 \% \mathrm{CI}$ : -0.09 to $0.01 ; \mathrm{P}=0.13)$. Conclusions: As a valid treatment for hypertension patients, Tai Chi exercise can decrease SBP, DBP, TG, LDL-C and increase NO.
\end{abstract}

\section{Introduction}

Hypertension is observed as the most common disease in primary health care of human, severe complications can be leaded by this disease, such as atherosclerotic complications including stroke, hypertensive renal disease, and hypertensive cardiovascular disease, renal inadequacy, coronary artery disease, and even the cardiac failure[1,2]. The American Heart Association suggested that the risk of hypertension can be reduced by the effective lifestyle modifications like regular exercise[3]. Tai Chi was ancient martial arts in Oriental cultures has been used for centuries. It has also been used as an exercise form and best adapted for older individuals of Asian heritage, to enhance body awareness and body balance. Tai Chi can lowered diastolic blood pressure (DBP) and systolic blood pressure (SBP) has been proved by a recent of trials, modulated lipid metabolism, and raised the NO index of patients with hypertension, and others comprehensive beneficial effects[4-16]. Tai Chi can benefit hypertension patients which supported by increasing evidence from RCTs, but there is no strictly evaluated evidence to confirm its function in hypertension patients health according to small size individual studies samples were short of strictly designed large size and inconsistent results RCTs. Clearly, an up-to-date meta-analysis and systematic review of this topic is needed. Therefore, we designed this study to sum up the actual evidence on the curative effect of Tai Chi exercise for the

\footnotetext{
${ }^{a}$ Corresponding author: E-mail:fuyan1010@163.com. Tel:177-2982-8135.

This research was supported by the School Youth Foundation Project of Chengdu University

(No.2080516037).
} 
therapy of hypertension patients.

\section{Methods}

\subsection{Strategy of search}

Two reviewers carried out a scientific search in the following 5 online network databases from 2000 to 2016 to retrieve potential studies independently: Science Direct, EBSCO, Pub Med, CNKI and Wanfang databases. The following search keywords were used: ("Tai Chi Quan" or "Tai Ji Quan" or "Tai Chi") AND ("gao xue ya" or "high blood pressure" or "hypertension" or "xue ya" or "blood pressure"). On the other side, we connected colleagues and experts in this field to predicate if there are any related ongoing or unpublished researches existed, and connected the authors of these researches to get detailed data as we needed.

\subsection{Eligibility criteria}

Only the study which should be RCTs intended to assess the availability of Tai Chi for the therapy of hypertension patient were considered.

In this review, the participants should meet at least one of the current or past exact definitions of hypertension[1]. The research objects in the study were the same elderly people. However, hypertension patients combined arrhythmia, severe coronary heart disease(CHD), hepatic failure, severe heart failure, or kidney failures were excluded. But age, sex or ethnic origin were not restricted.

Trials were compared Before Tai Chi exercise (BTC) versus After Tai Chi exercise (ATC).Do Tai Chi exercise at least 3 times a week, not less than 50 minutes. If the studies were case reports or reporting the same results were excluded.

\subsection{Data extraction}

Two different reviewers got the data from the primary researches independently. The extraction data form consisted of 4 parts: (1) the study's general information, (2) the detailed information of participants,(3) the information of the method used of Tai Chi, (4) the detailed information of Blood Pressure (BP), Total triglyceride (TG), Total cholesterol (TC), Heart rate (HR), Nitric Oxide(NO), High density lipoprotein cholesterol(HDL-C), Low density lipoprotein cholesterol(LDL-C) changes.

\subsection{Quality assessment}

We used the revised Jadad scale to evaluate the quality of each study. The highest score was 7 points, the higher the score, the higher the quality.

\subsection{Statistical analysis}

Revman5.2 software was used to analyze data and publication bias. Measurable data were provided by all of the included researches, and reported the weighted mean difference (WMD) with its 95\% confidence interval (CI). I squared $\left(\mathrm{I}^{2}\right)$ statistic was employed to assess heterogeneity and when $\mathrm{I}^{2}>$ $50 \%$, the heterogeneity was significant. The fixed effects model was taken to analyze the studies. We considered $\mathrm{P}<0.05$ to be statistically significant.

\section{Results}

\subsection{Document Indexing and Research characteristics}


We searched 76 articles, depending on the basis of literature into and exclusion the filtered criteria, finally, we got 13 studies in this review[4-16]. Figure 1 depicts the study selection's detailed process. Tables 1 shows the essential features of the included summarized themes and trials.

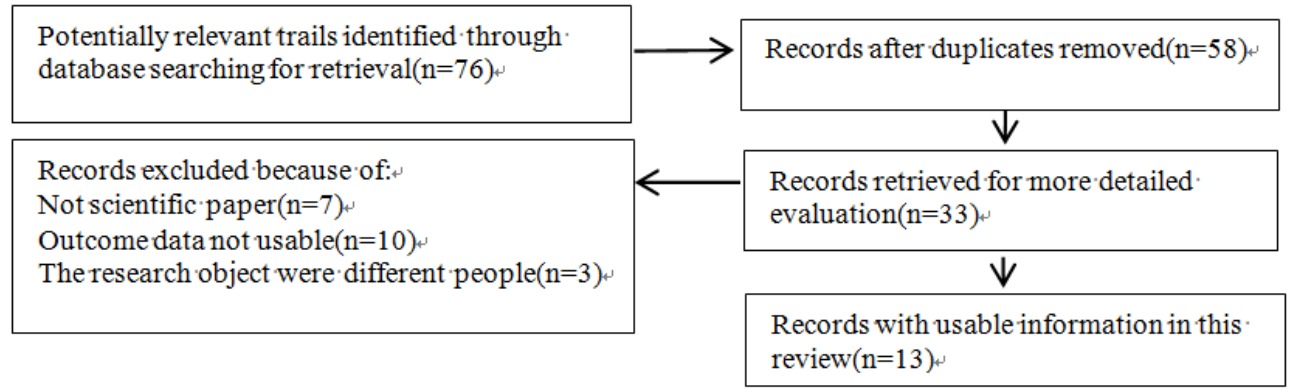

Figure 1. Study selection and identification process.

\subsection{The quality of the research's methodology}

The revised Jadad Scale was used to assess the quality of the studies. The score of the included subjects and trials are in Table 1.

Table 1. The included trials basic characteristics.

\begin{tabular}{|c|c|c|c|c|c|c|c|c|}
\hline References & Age(yrs) & $\begin{array}{l}\text { BT } \\
\text { C } \\
\text { (n) } \\
\end{array}$ & $\begin{array}{l}\text { AT } \\
\text { C } \\
(\mathrm{n}) \\
\end{array}$ & $\begin{array}{l}\text { Male/F } \\
\text { emale }\end{array}$ & Intervention & Treatment and duration & $\begin{array}{l}\text { Primary } \\
\text { outcomes }\end{array}$ & $\begin{array}{r}\text { Jadad } \\
\text { score }\end{array}$ \\
\hline $\begin{array}{l}\text { JEN-CHEN et } \\
\text { al. } \\
2003[1]\end{array}$ & $51.6 \pm 16.3$ & 44 & 37 & $19 / 18$ & $\begin{array}{c}\text { Yang-style Tai } \\
\text { Chi }\end{array}$ & $\begin{array}{l}\text { 3times/week, } 50 \text { minutes } \\
\text { /time, } 12 \text { weeks }\end{array}$ & $\begin{array}{l}(1)(2)(3)(6) \\
\quad(7)(8)\end{array}$ & 3 \\
\hline $\begin{array}{l}\text { Hui-Ming Lo et } \\
\text { al.2012[2] }\end{array}$ & $\begin{array}{c}58.47 \pm \\
7.46\end{array}$ & 37 & 27 & $15 / 12$ & $\begin{array}{c}\text { Yang-style Tai } \\
\text { Chi }\end{array}$ & $\begin{array}{l}\text { 3times/week, } 60 \text { minutes } \\
\text { /time, } 8 \text { weeks }\end{array}$ & (1) & 3 \\
\hline $\begin{array}{l}\text { Jing Sun et al. } \\
2015[3]\end{array}$ & $45 \sim 65$ & 150 & 136 & $117 / 19$ & Tai Chi & $3 \mathrm{~h} /$ week, 12 months & $\begin{array}{l}(1)(2)(3)(5) \\
(7)(8)\end{array}$ & 3 \\
\hline $\begin{array}{l}\text { WANG Xiao- } \\
\text { jun et al.2011[4] }\end{array}$ & $50 \sim 70$ & 30 & 30 & $9 / 21$ & Tai Chi & $\begin{array}{l}\text { 5times/week, 60minutes } \\
\text { /time,16weeks }\end{array}$ & $(1)(2)$ & 2 \\
\hline $\begin{array}{l}\text { JIN Zhen-yang } \\
\text { ea al.2012[5] }\end{array}$ & $61 \pm 3.7$ & 80 & 80 & $57 / 23$ & $\begin{array}{l}\text { 24-style } \\
\text { Tai Chi }\end{array}$ & $\begin{array}{l}\text { 7times/week,2h/time, } 6 \\
\text { months }\end{array}$ & (2) & 1 \\
\hline $\begin{array}{l}\text { Sun Feng et al. } \\
2014[6]\end{array}$ & $60 \sim 70$ & 45 & 38 & $14 / 24$ & $\begin{array}{l}\text { 24-style } \\
\text { Tai Chi }\end{array}$ & $\begin{array}{l}7 \text { times/week, } 2 \mathrm{~h} / \text { time, } 8 \\
\text { weeks }\end{array}$ & $(1)(2)(3)$ & 3 \\
\hline $\begin{array}{l}\text { He You-ping et } \\
\text { al.2012[7] }\end{array}$ & $35 \sim 64$ & 52 & 52 & $28 / 24$ & $\begin{array}{l}\text { Chen-style } \\
\text { Tai Chi }\end{array}$ & $\begin{array}{l}\text { 7times/week, } 80 \text { minutes } \\
/ \text { time,3months }\end{array}$ & $(2)(4)$ & 2 \\
\hline $\begin{array}{l}\text { Xie Hui-juan et } \\
\text { al.2014[8] }\end{array}$ & $60 \sim 70$ & 50 & 50 & $25 / 25$ & $\begin{array}{l}\text { 24-style } \\
\text { Tai Chi }\end{array}$ & $\begin{array}{l}\text { 5times/week, } 60 \text { minutes } \\
\text { /time, } 12 \text { weeks }\end{array}$ & $(1)(4)$ & 1 \\
\hline $\begin{array}{l}\text { Mao Hong-ni et } \\
\text { al.2008[9] }\end{array}$ & $\begin{array}{c}63.16 \pm \\
6.43\end{array}$ & 50 & 50 & $30 / 20$ & Tai Chi & $\begin{array}{c}5 \sim 6 \text { times/week, } 60 \text { minut } \\
\text { es/time, } 8 \text { weeks }\end{array}$ & (4) & 1 \\
\hline $\begin{array}{l}\text { He Jing-he et } \\
\text { al.2011[10] }\end{array}$ & $51.6 \pm 5.3$ & 33 & 33 & NS & $\begin{array}{c}\text { 24/42/48-style } \\
\text { Tai Chi }\end{array}$ & $\begin{array}{l}\text { 6times/week, } 40 \sim 50 \mathrm{~min} \\
\text { utes/time, } 20 \text { weeks }\end{array}$ & $(1)(2)(3)(6)$ & 2 \\
\hline $\begin{array}{l}\text { Mao Hong-ni et } \\
\text { al.2006[11] }\end{array}$ & $45 \sim 72$ & 62 & 62 & $15 / 47$ & $\begin{array}{l}\text { 24-style } \\
\text { Tai Chi }\end{array}$ & $\begin{array}{c}\text { 6times/week, } 60 \text { minutes } \\
\text { /time,8weeks }\end{array}$ & $(1)(2)(4)$ & 2 \\
\hline $\begin{array}{l}\text { Li Chuan-wu et } \\
\text { al.2007[12] }\end{array}$ & $58 \pm 5$ & 16 & 16 & $16 / 0$ & $\begin{array}{l}\text { 24/48-style } \\
\text { Tai Chi }\end{array}$ & $\begin{array}{c}\text { 5times/week,60minutes } \\
\text { /time,6months }\end{array}$ & $(5)(6)(7)$ & 1 \\
\hline $\begin{array}{l}\text { Zhong Yun-jian } \\
\text { et al.2009[13] }\end{array}$ & $41 \sim 46$ & 14 & 14 & NS & $\begin{array}{l}\text { 83-style } \\
\text { Tai Chi }\end{array}$ & $\begin{array}{c}\text { 6times/week,60minutes } \\
\text { /time, } 16 \text { weeks }\end{array}$ & $(2)(5)(6)(8)$ & 2 \\
\hline
\end{tabular}

Abbreviation: NS: Not given; BTC: Before Tai Chi exercise; ATC: After Tai Chi exercise;

(1)SBP; (2)DBP; (3)HR; (4)NO; (5)TC; (6)TG; (7)LDL-C; (8)HDL-C. 


\subsection{Meta-analysis results}

\subsubsection{SBP and DBP}

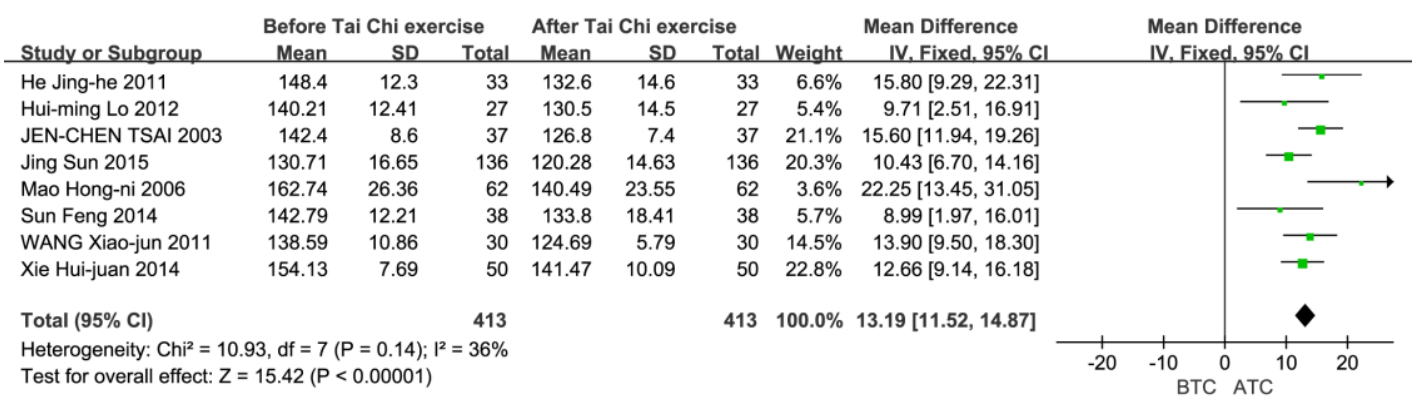

Figure 2. The forest figure of Systolic blood pressure.

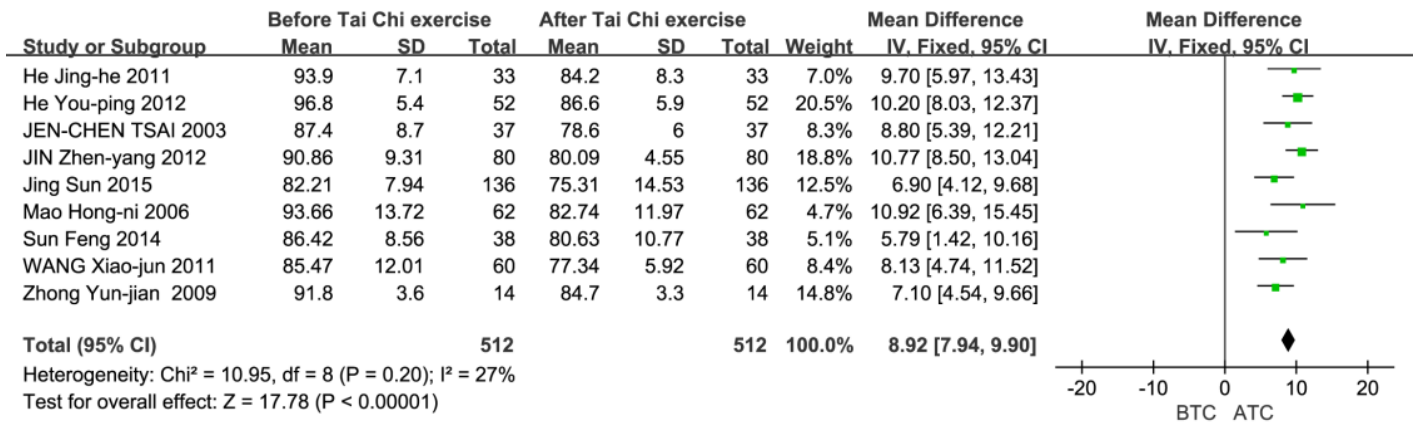

Figure 3. The forest figure of Diastolic blood pressure.
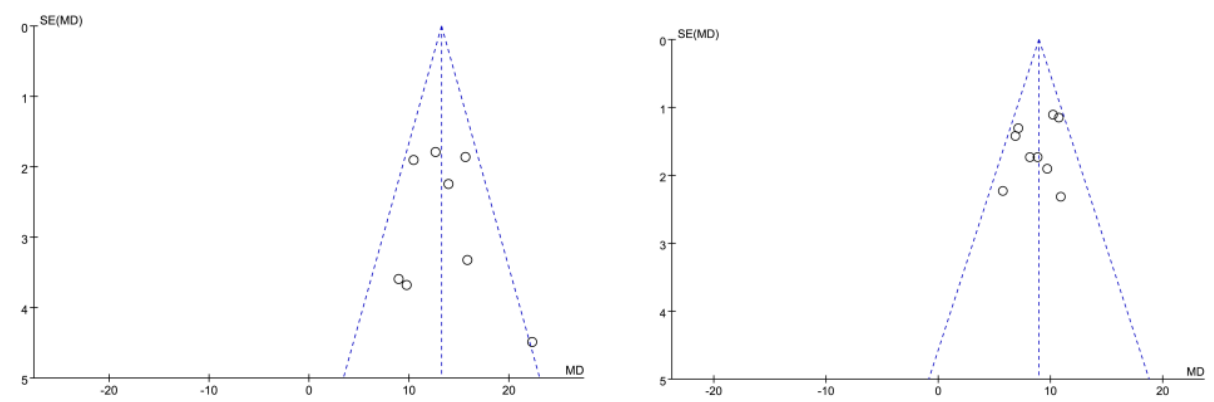

Figure 4. The funnel figure of Systolic blood pressure. Figure 5. The funnel figure of Diastolic blood pressure.

There is no risk of publication bias through the funnel figure (Figs.4\&5). These trials demonstrated no significant heterogeneity with $\mathrm{I}^{2}$ values ranging from 27 to $36 \%$ (Figs.2\&3). The meta-analysis found that after Tai Chi exercise (ATC) can significantly reduce the SBP (WMD $=13.19 \mathrm{mmHg}$; 95\%CI: 11.52 to $14.87 ; \mathrm{P}<0.0001)$ and $\mathrm{DBP}(\mathrm{WMD}=8.92 \mathrm{mmHg} ; 95 \% \mathrm{CI}: 7.94$ to $9.90 ; \mathrm{P}<0.0001)$ compared to before Tai Chi exercise(BTC)(Figure 2\& Figure 3).

\subsubsection{Other outcomes}

Other outcomes: HR, NO, TC, TG, LDL-C, HDL-C.(1)HR. 3 trials evaluated the effect of Tai Chi on HR. Demonstrated no significant change of $\mathrm{HR}(\mathrm{WMD}=1.64 ; 95 \% \mathrm{CI}$ : -0.51 to 3.97 ; $\mathrm{P}=0.14)$ by ATC 
was identified compared BTC.(2)NO. 5 trials evaluated the effect of Tai Chi on NO.ATC significantly improved the content of $\mathrm{NO}(\mathrm{WMD}=-7.98 \mathrm{mmol} / \mathrm{L} ; 95 \% \mathrm{CI}$ : -10.63 to -5.33 ; $\mathrm{P}<0.0001$ ). (3)TC. 3 trials evaluated the effect of Tai Chi on TC. Demonstrated no significant change of TC (WMD = $0.03 \mathrm{mmol} / \mathrm{ml} ; 95 \% \mathrm{CI}:-0.22$ to $0.17 ; \mathrm{P}=0.80$ ) by ATC was identified compared BTC.(4)TG. 4 trials evaluated the effect of Tai Chi on TG. ATC significantly reduced the TG content(WMD $=0.22 \mathrm{mmol} / \mathrm{ml} ; 95 \% \mathrm{CI}: 0.06$ to $0.38 ; \mathrm{P}=0.006)$.(5)LDL-C. 3 trials evaluated the effect of Tai Chi on LDL-C. ATC significantly decreased the content of LDL-C( WMD $=0.20 \mathrm{mmol} / \mathrm{ml} ; 95 \% \mathrm{CI}: 0.13$ to 0.26; $\mathrm{P}<0.0001) .(6) H D L-C .3$ trials evaluated the effect of Tai Chi on HDL-C. ATC demonstrated no significant change of $\mathrm{HDL}-\mathrm{C}(\mathrm{WMD}=-0.04 \mathrm{mmol} / \mathrm{ml} ; 95 \% \mathrm{CI}$ : -0.09 to $0.01 ; \mathrm{P}=0.13)$.

\section{Discussions}

\subsection{Summary of evidence}

Tai Chi, as an exercise for health in a wide age range, has been used for several centuries, especially popular in the elderly[4]. Of course, we need to identify a suitable exercise regimen targeted to maintain and improve hypertension patients health[5]. This study researched if Tai Chi is an safe and effective therapy methods of hypertension patients.

In conformity with the outcome measures from $13 \mathrm{RCTs}$ with a total of 625 participants, this metaanalysis and systematic review study is to give an objective assessment of Tai Chi for the arrangement of hypertension patients. The meta-analysis found that after Tai Chi exercise (ATC) showed a clinically obvious improvement on the SBP (decreased by $13.19 \mathrm{mmHg}$ ), DBP (decreased by 8.92 $\mathrm{mmHg}$ ), NO (increased by $7.98 \mathrm{mmol} / \mathrm{L}$ ), TG (decreased by $0.22 \mathrm{mmol} / \mathrm{ml}$ ) and LDL-C (decreased by $0.20 \mathrm{mmol} / \mathrm{ml})$.NO is a very important biological messenger and signal molecule, also it is a formidable vasodilator factor ${ }^{[14]}$. This study shows that Tai Chi exercise can increase the content of NO. Research found that hypertension and dyslipidemia are frequently existing together, and people with these conditions will have an increased cardiovascular disease risk[17-19]. This study shows that Tai Chi exercise can modulate lipid metabolism. We need to concern how long and how often Tai Chi exercise should be practiced for the therapy of hypertension patients? In this study, all of the trials duration included are ranged from 8 weeks to 1 year. So, we recommended that Tai Chi exercise should be practiced at least for 8 weeks and at least 3times/week. Hence, the combined results show that Tai Chi exercise is an effective and relatively-safe supplemental method for the therapy of hypertension patients.

\subsection{Limitations}

In spite of the significant active results of Tai Chi exercise for the therapy of hypertension patients, a lot of limitations also need to be noted. First, most of the trials included did not report the sample sizes calculating methods, and whether the number of participants involved met the research requirements or not is still not clear. Second, the small sample sizes and generally poor methodological quality limited the strength feasibility and generally poor methodological quality of the clinical evidence[15,16]. Third, because we only enrolled Asian hypertensive patients, there were no data about the effectiveness of Tai Chi exercise on other national's BP. So, the potential selection bias couldn't be ruled out. Fourth, the included trails used different styles of Tai Chi exercise. Finally, although the effects of Tai Chi exercise on BP outcomes were reported, but there are still a lot of recessive results that were difficult to be published. Therefore, further studies are needed.

\section{Conclusions}

This study shows that Tai Chi exercise is an effective treatment for hypertension patients. This can decrease SBP, DBP, TG, LDL-C and increase NO. However, more reasonable designed RCTs are still 
warranted before it can be used, and more methodologically rigorous researches are needed to prove Tai Chi's real clinical benefits, and needed to explore the potential mechanism of Tai Chi.

\section{References}

1. James PA, Oparil S, Carter BL, et al. 2014 evidence-based guideline for the management of high blood pressure in adults: report from the panel members appointed to the Eighth Joint National Committee (JNC 8). J Am Med Assoc311:507-20(2014).

2. Papadakis MA. Current Medical Diagnosis \& Treatment 2004, 43rd ed. New York: McGraw-Hill. 401(2004).

3. Eckel RH, Jakicic JM, Ard JD, et al. 2013 AHA/ACC guideline on lifestyle management to reduce cardiovascular risk: a report of the American College of Cardiology/American Heart Association task force on practice guidelines. Circulation 129:S76-99(2014).

4. JEN-CHEN TSAI,WEI-HSIN WANG,et al. The Beneficial Effects of Tai Chi Chuan on Blood Pressure and Lipid Profile and Anxiety Status in a Randomized Controlled Trial. THE JOURNAL OF ALTERNATIVE AND COMPLEMENTARY MEDICINE 9:747-754(2003).

5. Hui-Ming Lo,et al.A Tai Chi exercise programme improved exercise behavior and reduced blood pressure in outpatients with hypertension. International Journal of Nursing Practice 18: 545551(2012).

6. Jing Sun,et al.Community-Based MindeBody Meditative Tai Chi Program and Its Effects on Improvement of Blood Pressure, Weight, Renal Function, Serum Lipoprotein, and Quality of Life in Chinese Adults With Hypertension. Am J Cardiol 116:1076e1081(2015).

7. WANG Xiao-jun,et al. Empirical Study of Taijiquan Interventions on the Prevention and cure of Hypertension. Journal of Beijing Sport University 9:75-77(2011).

8. JIN Zhen-yang, et al. Effect of Tai Chi on the hypertension and blood lipid level among middle aged people. Modern Preventive Medicine39:4468-4471(2012).

9. Sun Feng et al. Intervention effect of taijiquan exercise on senile hypertension. Chinese journal of gerontology 34:6862-6864(2014).

10. He You-ping et al. The Effect and Mechanism of Taijiquan on Primary Hypertension. Journal of Anhui Normal University (Natural Science) 35:83-87(2012).

11. Xie Hui-juan et al. Gaseous Signal Molecular Mechanism of Taijiquan's Intervention in Aged Essential Hypertension. Journal of Wuhan Institute of Physical Education48:51-63(2014).

12. Mao Hong-ni et al. Tai chi balance cycle of NO/ET in patients with essential hypertension. Chinese journal of gerontology 28:508-509(2008).

13. He Jing-he et al. Taijiquan research on effect of intervention in patients with essential hypertension. Chinese Journal of Rehabilitation Medicine 26:968-971(2011).

14. Mao Hong-ni et al. Effect of Tai Chi exercise on blood pressure, plasma nitrogen monoxidum and endothelin in hypertensive patients. Chinese Journal of Clinical Rehabilitation 48:65-67(2006).

15. Li Chuan-wu et al. Effect of Taijiquan on endothelial diastolic function in the elder ly. Journal of Clinical Rehabilitative Tissue Engineering Research 27:5414-5416(2007).

16. Zhong Yun-jian et al. Effects of single acute Taijiquan exercise on essential hypertension. J Fourth MilMed Univ 30:3136-3139(2009).

17. Haffner SM, Miettinen H, Gaskill SP, Stern MP. Metabolic precursors of hypertension. The San Antonio heart study. Arch Intern Med 156:1994e2001(1996).

18. Oparil S,Zaman MA,Calhoun DA. Pathogenesis of hypertension. Ann Intern Med 139:761e776. (2003).

19. Stamler J, et al. Prevalence and prognostic significance of hypercholesterolemia in men with hypertension. Prospective data on the primary screeners of the Multiple Risk Factor Intervention Trial. Am J Med80:33e39(1986). 